\title{
High Sugar-Fat Diet Induces Metabolic-Inflammatory Disorders Independent of Obesity Development
}

\author{
Jéssica Leite Garcia ${ }^{*}$, Fabiane Valentini Francisqueti1, Ana Paula da Costa Rodrigues Ferraz ${ }^{1}$, \\ Artur Junio Togneri Ferron', Mariane Róvero Costa1, Cristina Schmitt Gregolin1, \\ Dijon Henrique Salomé de Campos' ${ }^{1}$, Klinsmann Carolo dos Santos ${ }^{1}$, Igor Otávio Minatel1,2, \\ Camila Renata Corrêa ${ }^{1}$
}

${ }^{1}$ Medical School, São Paulo State University (UNESP), Botucatu, Brazil
${ }^{2}$ Institute of Bioscience, São Paulo State University (UNESP), Botucatu, Brazil
Email: *jessica.leite@unesp.br

How to cite this paper: Garcia, J.L., Francisqueti, F.V., da Costa Rodrigues Ferraz, A.P., Ferron, A.J.T., Costa, M.R., Gregolin, C.S., de Campos, D.H.S., dos Santos, K.C., Minatel, I.O. and Corrêa, C.R. (2019) High Sugar-Fat Diet Induces Metabolic-Inflammatory Disorders Independent of Obesity Development. Food and Nutrition Sciences, 10, 664-677.

https://doi.org/10.4236/fns.2019.106049

Received: May 17, 2019

Accepted: June 23, 2019

Published: June 26, 2019

Copyright $\odot 2019$ by author(s) and Scientific Research Publishing Inc. This work is licensed under the Creative Commons Attribution International License (CC BY 4.0).

http://creativecommons.org/licenses/by/4.0/

\begin{abstract}
Background: The modern dietary habit, which is rich in refined carbohydrates and saturated fats, increases the risk of chronic diseases due to the proinflammatory effect of these nutrients. Aim: To evaluate the impact of high sugar-fat diet in the development of metabolic-inflammatory disorders in non-obese animals. Methods: Male Wistar rats were distributed into two groups according to the diet: control and high sugar-fat for 30 weeks. It was analyzed: dietary efficiency; chow, water and caloric intake; metabolic and hormonal profile in plasma and inflammatory cytokines in epididymal adipose tissue. Data were compared by Student's $t$ test or by Mann-Whitney $U$ test with $\mathrm{p}<0.05$ as significant. Results: HSF presented lower chow intake, higher water consumption and dietary efficiency with no difference in the caloric intake. The final body weight (FBW) and weight gain (WG) were lower in the HSF group and there was no difference in the adiposity index (AI). HSF diet-induced hyperglycemia and hyperinsulinemia with no difference for Homeostatic Model Assessment for Insulin Resistance (HOMA-IR). Triglycerides, uric acid, adiponectin and leptin levels were higher in the HSF group. The HSF group showed increased interleukin-6 (IL-6) and tumoral necrosis factor-alpha (TNF- $\alpha$ ) levels in epidydimal adipose tissue. The urinary protein-creatinine ratio and albuminuria were higher in the HSF group. Conclusion: HSF diet intake is directly involved in the development of metabolic-inflammatory disorders independent of obesity, dissociating the view that increased adiposity is the major risk factor for complications commonly found in obese individuals.
\end{abstract}




\section{Keywords}

High Sugar-Fat Diet, Western Diet, Adipose Tissue, Cytokines, Metabolic Disorders

\section{Introduction}

The literature suggests that the metabolic syndrome is consequence of adipose tissue-generated molecules which initiates a state of low-grade inflammation, responsible by metabolic, hemodynamic and vascular consequences [1]. In a condition of positive energetic balance, the caloric excess is stored in adipose tissue, which also has an endocrine function, secreting different adipokines [2]. However, the adipocyte hypertrophy process leads to adipose tissue dysfunction, characterized by deregulation in the adipokines secretion. Within this context, there is an increase in the tumoral necrosis factor-alpha (TNF- $\alpha$ ), interleukin- 6 (IL-6), monocyte chemoattractant protein-1 (MCP-1), leptin and resistin levels and a reduction of adiponectin, a protective and anti-inflammatory agent [3] [4]. This proinflammatory scenario is associated with the development of insulin resistance, type II Diabetes Mellitus, cardiovascular and kidney diseases [5] [6].

On the other hand, a new perspective has discussed the hypothesis regarding the diet direct effect on disorders development [7]. The Mediterranean diet recommends a sufficient intake of whole grains, vegetables, fruit and fish, olive oil, and a reduced intake of red meat and high fat dairy products in order to reduce the risk of diseases [8]. In addition, some nutrients have been reported to reduce the risk of inflammation, among them complex carbohydrates [9], polyunsaturated fatty acid [10], dietary fiber [11], vitamin E [12] and vitamin C [13]. In contrast, the modern dietary habit, referred as Western Diet, which is rich in refined carbohydrates, saturated fats, and sweetened beverages [14] could increase the risk of chronic diseases and mortality, and leads to a life quality impairment due to the proinflammatory effect of these nutrients [15]. These reports show that dietary quality may be a key factor for the prevention and/or development of diseases, becoming an emergent health topic that deserves to be investigated.

The association between obesity and the development of diseases due to the adipose tissue dysfunction is well characterized [16] [17] [18] [19]. However, since the rates of chronic diseases are increasing also in non-obese individuals [20] [21], to clarify the direct effect of nutrients on these illnesses will allow future interventions. The aim of this study was to evaluate the impact of high sugar-fat diet in the development of metabolic-inflammatory disorders in non-obese animals.

\section{Methods}

\subsection{Animals and Experimental Protocol}

All the experiments and procedures were approved by the Animal Ethics Com- 
mittee from Botucatu Medical School (1233/2017) and performed in accordance with the National Institute of Health's Guide for the Care and Use of Laboratory Animals [22]. Male Wistar rats ( \pm 45 days) were randomly distributed into two experimental groups according to the diet: control $(\mathrm{C}, \mathrm{n}=8)$ and high sugar-fat (HSF, $n=27$ ). The diets and water were offered ad libitum for 30 weeks. The $\mathrm{C}$ diet contained soybean meal, sorghum, soybean peel, dextrin, soy oil, vitamins, and minerals. The HSF diet contained soybean meal, sorghum, soybean peel, dextrin, sucrose, fructose, lard, vitamins, and minerals, plus $25 \%$ sucrose in the drinking water (Table 1). Both diets were produced according to Francisqueti et al. (2017) [23]. All the animals were kept in a controlled temperature $\left(24^{\circ} \mathrm{C} \pm\right.$ $\left.2^{\circ} \mathrm{C}\right)$ and relative humidity $(55 \% \pm 5 \%)$ environment and in $12 \mathrm{~h}$ light-dark cycle.

\subsection{Groups Characterization and Composition}

At the end of the experiment, a cut-off criterion based on the adiposity index (AI) was established for the group characterization [24] [25]. AI represents the fat percentage, which is the most appropriate variable to classify the presence or

Table 1. Diet composition and nutritional values.

\begin{tabular}{|c|c|c|}
\hline Components & $\mathrm{C}$ & HSF \\
\hline Soybean meal (g/kg) & 335 & 340 \\
\hline Sorghum (g/kg) & 278 & 80 \\
\hline Soy hulls (g/kg) & 188 & 116 \\
\hline Dextrin $(\mathrm{g} / \mathrm{kg})$ & 146 & 20 \\
\hline Sucrose $(\mathrm{g} / \mathrm{kg})$ & - & 80 \\
\hline Fructose $(\mathrm{g} / \mathrm{kg})$ & - & 180 \\
\hline Soybean oil (g/kg) & 14 & - \\
\hline Lard (g/kg) & - & 154 \\
\hline Minerals (g/kg) & 25 & 25 \\
\hline Salt (g/kg) & 4 & 8 \\
\hline \multicolumn{3}{|l|}{ Nutritional values } \\
\hline Protein (\% of ingredients) & 20.0 & 18.0 \\
\hline Carbohydrate (\% of ingredients) & 60.0 & 53.5 \\
\hline Fat (\% of ingredients) & 4.00 & 16.5 \\
\hline$\%$ of unsatured & 69.0 & 47.0 \\
\hline$\%$ of saturated & 31.0 & 53.0 \\
\hline$\%$ Energy from protein & 22.9 & 16.6 \\
\hline$\%$ Energy from carbohydrate & 66.8 & 49.2 \\
\hline$\%$ Energy from fat & 10.4 & 34.2 \\
\hline Energy (kcal/g) & 3.59 & 4.35 \\
\hline
\end{tabular}

C: Control; HSF: High sugar-fat. Values do not consider water plus sucrose. 
not of obesity in experimental models. Since the aim of this study was to evaluate animals submitted to HSF diet that did not become obese, this variable was used to exclude obese animals. A 95\% confidence interval (CI) was used for the average of the adiposity index and the separation point (SP) was the midpoint between the upper limit of the $\mathrm{C}$ group and the lower limit of the HSF group (SP =4.58). The animals with AI above the SP were excluded. The final composition of the groups analyzed in this study was the following: group $\mathrm{C}, \mathrm{n}=7$ and group HSF, $\mathrm{n}=8$.

\subsection{Biological Material and Euthanasia}

At the 30th week, preceding euthanasia, 24 hours urine samples were collected and the total volume of diuresis was measured. Subsequently all the samples were centrifuged $\left(3000 \mathrm{rpm}\right.$ at $4^{\circ} \mathrm{C}$ for 10 minutes; Eppendorf Centrifuge 5804-R, Hamburg, Germany), aliquoted and stored at $-80^{\circ} \mathrm{C}$. At the end of 30 weeks, the animals were fasted for 8 hours and then anesthetized with Xylazine (1 mg/kg, i.p.) and Ketamine (100 mg/kg, i.p.) (Syntec, Rhobifarma Indústria Farmacêutica Ltda., Hortolândia, São Paulo, Brazil) and euthanized by decaptation after foot reflex verification. Blood samples were collected in conic plastic tubes of $15 \mathrm{~mL}$ containing the anticoagulant, ethylenediaminetetraacetic acid (EDTA) in the proportion of $0.1 \mathrm{~mL}$ for each $5 \mathrm{~mL}$ of blood, followed by centrifugation $\left(3000 \mathrm{rpm}\right.$ at $4^{\circ} \mathrm{C}$ for 10 minutes, Eppendorf ${ }^{\circledast}$ Centrifuge 5804-R, Hamburg, Germany) to obtain plasma. The epididymal, retroperitoneal and visceral fat deposits were dissected and weighed. The epididymal deposit was stored in sterile cryotubes (Alfa Ltda-EPP, Ipiranga, São Paulo, Brazil). The collected materials were stored at $-80^{\circ} \mathrm{C}$ until the analysis.

\subsection{Nutritional Status and Body Composition}

The nutritional status was evaluated by dietary efficiency, and chow, water and caloric intake. Food and water intake were daily calculated from the individual leftovers of each animal. Caloric intake was determined by multiplying the energy value of each diet $(\mathrm{g} \times \mathrm{Kcal})$ by the daily food consumption. For the HSF group, the caloric intake also included the calories from drinking water. In order to analyze the capacity to convert the ingested energy in body weight, the dietary efficiency was calculated by dividing the total gain of body weight by the total energy ingested. Weight gain (WG) was calculated by the final body weight (FBW) minus the initial body weight (IBW). After the experimental period, the deposits of retroperitoneal, visceral and epididymal fat were dissected and weighted and the AI (\%) was calculated by summing the weight of the deposits divided by body weight and multiplied by 100 , giving the result in percentage of fat [26].

\subsection{Metabolic and Hormonal Profile}

To evaluate the disorders leaded by the diet, it was analyzed the following parameters: 


\subsubsection{Metabolic}

Plasma glucose, triglycerides, uric acid, (BioClin, Quibasa Química Básica Ltda., Belo Horizonte, Minas Gerais, Brazil); albuminuria, proteinuria and creatinine urinary $\left(\mathrm{CELM}^{\otimes}\right.$, Barueri, São Paulo, Brazil) were measured by colorimetric-enzymatic method in automatic enzymatic analyzer system (Chemistry Analyzer BS-200, MindrayMedical International Limited, Shenzhen, China). Protein and creatinine urinary were measured to obtain protein/creatinine ratio [27].

\subsubsection{Hormonal}

Insulin, adiponectin (EMD Millipore Corporation, Billerica, MA, USA) and leptin (Crystal Chem, Elk Grove Village, IL, USA) were analyzed in plasma by ELISA. The readings were performed on Spectra Max 190 microplate reader (Molecular Devices ${ }^{\circledast}$, Sunnyvale, CA, USA). The Homeostatic Model Assessment for Insulin Resistance (HOMA-IR), which allows to evaluate the insulin resistance, was calculated according to the following formula [28]:

$$
\text { fasting insulin }(\mu \mathrm{UI} / \mathrm{mL}) \times \text { fasting glucose }(\mathrm{mmol} / \mathrm{L}) / 22.5
$$

\subsection{Adipose Tissue Inflammation}

The analyzes were performed in the epididymal adipose tissue once it reflects the visceral adipose tissue behavior [29]. The tissue samples were homogenized in phosphate-buffered saline (PBS) at 1:10 (sample: buffer) and the supernatant was used to measure the IL- 6 and TNF- $\alpha$ cytokines levels by ELISA (EMD Millipore Corporation, Billerica, MA, USA). Readings were performed on Spectra Max 190 microplate reader (Molecular Devices ${ }^{\oplus}$, Sunnyvale, CA, USA). Total proteins (BioClin, Quibasa Química Básica Ltda., Belo Horizonte, Minas Gerais, Brazil) were measured in the supernatant by a colorimetric-enzymatic method and analyzed in automatic enzymatic analyzer system (Chemistry Analyzer BS-200, MindrayMedical International Limited, Shenzhen, China). The results are expressed in $\mathrm{pg} / \mathrm{g}$ of protein.

\subsection{Statistical Analysis}

Parametric data are presented as means \pm standard deviation and compared by Student's $\mathrm{t}$ test. Non-parametric data are presented as median (interquatile range) and compared by Mann-Whitney $U$ test. The software used was Sigma Plot version 12.0 for Windows (Systat Software Inc., San Jose, CA, United States). A p value $<0.05$ was considered as statistically significant.

\section{Results}

\subsection{Nutritional Status and Body Composition}

Table 2 shows the nutritional status and body composition of the animals. The chow intake was lower in HSF group accompanied by higher water intake. There was no difference in the caloric intake between the groups and the dietary efficiency was decreased in HSF group. The final body weight and weight gain 
Table 2. Nutritional status and body composition.

\begin{tabular}{cccc}
\hline Parameters & C & HSF & p value \\
\hline Chow intake (g/day) & $24.0(22.6-27.8)$ & $8.52(7.83-9.59)$ & $\mathrm{p}<0.001^{*}$ \\
Water intake (mL/day) & $36.0 \pm 5.47$ & $50.0 \pm 5.98$ & $\mathrm{p}<0.001^{\star}$ \\
Calori intake (kcal/day) & $88.9 \pm 9.51$ & $86.3 \pm 7.39$ & $\mathrm{p}=0.691$ \\
Dietary efficiency (g/kcal) & $0.016 \pm 0.00$ & $0.012 \pm 0.00$ & $\mathrm{p}<0.001^{\star}$ \\
IBW (g) & $183 \pm 13.9$ & $171 \pm 9.38$ & $\mathrm{p}=0.084$ \\
FBW (g) & $492 \pm 54$ & $405 \pm 30$ & $\mathrm{p}=0.002^{\star}$ \\
WG (g) & $302 \pm 53.0$ & $231 \pm 37.5$ & $\mathrm{p}=0.010^{\star}$ \\
TF (g) & $21.6 \pm 1.85$ & $19.3 \pm 2.5$ & $\mathrm{p}=0.095$ \\
VAT (g) & $4.94 \pm 1.06$ & $4.69 \pm 0.69$ & $\mathrm{p}=0.596$ \\
EAT (g) & $8.05 \pm 0.91$ & $5.93 \pm 1.34$ & $\mathrm{p}=0.006^{*}$ \\
RAT (g) & $8.58 \pm 1.15$ & $8.77 \pm 1.39$ & $\mathrm{p}=0.787$ \\
AI (\%) & $4.46 \pm 0.36$ & $4.79 \pm 0.43$ & $\mathrm{p}=0.142$ \\
\hline
\end{tabular}

C: control; HSF: high sugar-fat; IBW: initial body weight; FBW: final body weight; WG: weight gain; TF: total fat; VAT: visceral adipose tissue; EAT: epididymal adipose tissue; RAT: retroperitoneal adipose tissue; AI: adiposity index. Data are presented as means \pm standard deviation or as median (interquartile range). * indicates $\mathrm{p}<0.05$.

were lower in the HSF group and there was no difference in the adiposity index between the groups.

\subsection{Metabolic and Hormonal Profile}

The HSF diet induced hyperglycemia and hyperinsulinemia; however, there was no difference for HOMA-IR between the groups (Figure 1). Triglycerides and uric acid (Figure 2) were higher in the HSF group as well as adiponectin and leptin levels (Figure 3).

\subsection{Adipose Tissue Inflammation}

The HSF group showed increased levels of the proinflammatory cytokines, IL-6 and TNF- $\alpha$, in adipose tissue (Figure 4).

\subsection{Renal Injury}

The urinary protein-creatinine ratio and albuminuria were higher in the HSF group (Figure 5).

\section{Discussion}

The aim of this study was to evaluate the impact of high sugar-fat diet in the development of metabolic-inflammatory disorders in non-obese animals. The group submitted to HSF diet presented relevant metabolic, hormonal and inflammatory changes usually found in obesity and associated with increased adiposity [30]. According to the literature, the major risk factor for the obesity and obesity-related disorders development is the intake of processed foods rich in 


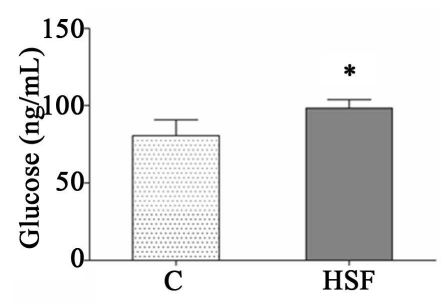

(a)

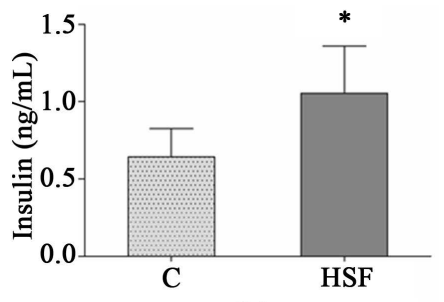

(b)

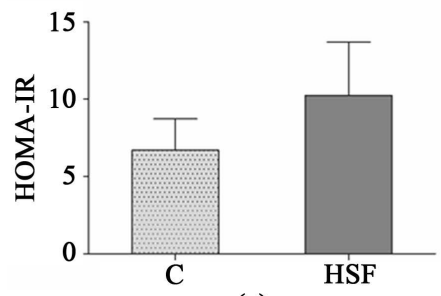

(c)

Figure 1. (a) Glucose; (b) Insulin and (c) HOMA-IR. C (Control); HSF (High Sugar-Fat) groups; HOMA-IR: Homeostatic Model Assessment for Insulin Resistance. ${ }^{*}$ indicates $\mathrm{p}$ $<0.05$.

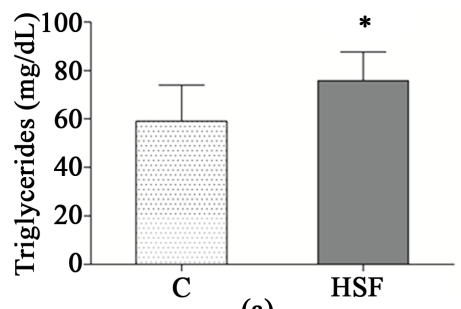

(a)

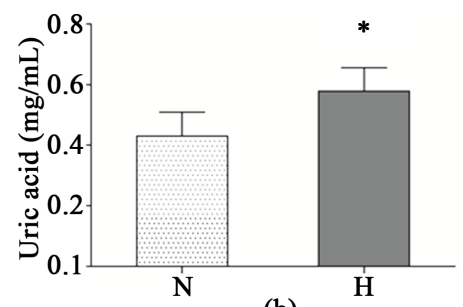

(b)

Figure 2. (a) Triglycerides and (b) Uric acid. C (Control) and HSF (High Sugar-Fat) groups. ${ }^{*}$ statistical difference to $\mathrm{p}<0.05$.
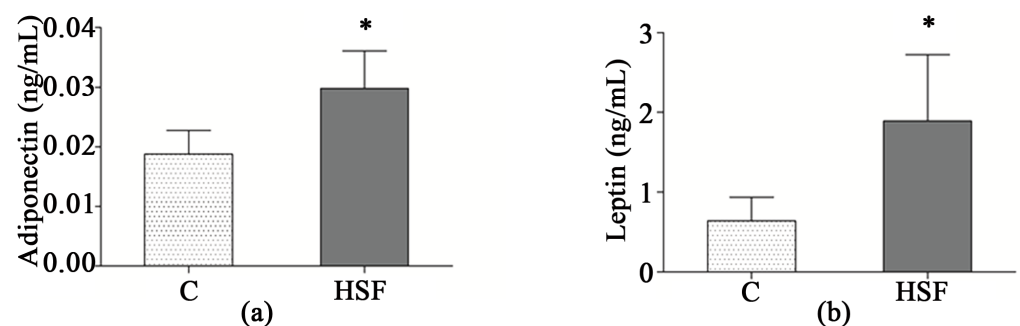

Figure 3. (a) Adiponectin and (b) Leptin levels. C (Control); HSF (High Sugar-Fat) groups. ${ }^{*}$ indicates $\mathrm{p}<0.05$.
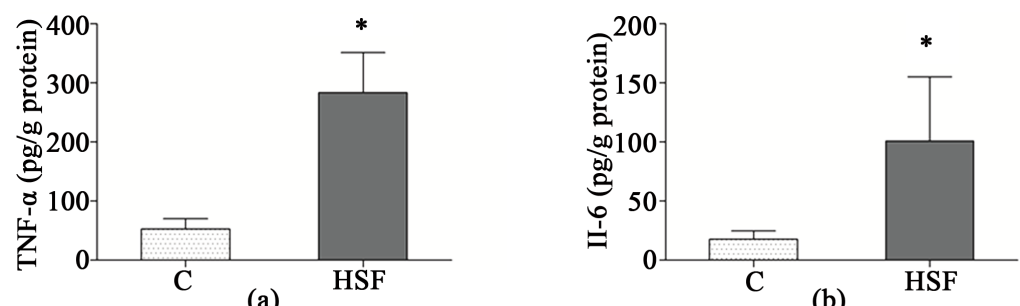

Figure 4. (a) Adipose tissue TNF- $\alpha$ and (b) IL-6. TNF- $\alpha$ : Tumor necrosis factor alpha; IL-6: interleukin-6; C (Control); HSF (High Sugar-Fat) groups. ${ }^{*}$ indicates $\mathrm{p}<0.05$. 


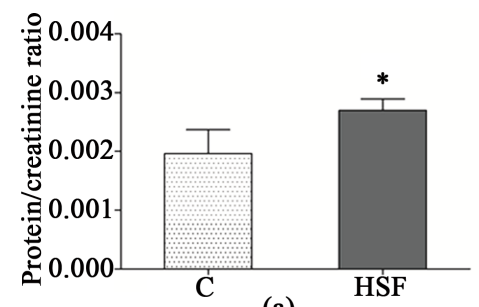

(a)

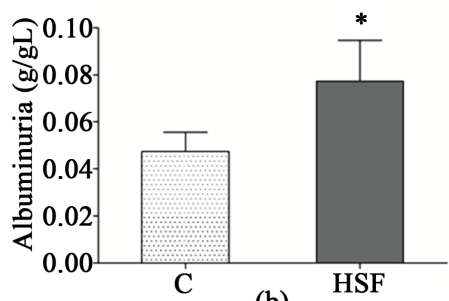

(b)

Figure 5. (a) Protein/creatinine ratio; (b) Albuminuria. C (Control) and HSF (High Sugar-Fat) groups. ${ }^{\star}$ indicates $\mathrm{p}<0.05$.

sugars and fats [5]. However, once in this study the HSF group presented adiposity index similar to $\mathrm{C}$ group, all the disorders were independent of adiposity gain.

One of the consequences of the chronic high sugar-fat diet intake is the occurrence of insulin resistance, which favors the onset of type II Diabetes Mellitus [30]. Although HSF group did not present difference in HOMA-IR index, the animals presented high levels of glucose and insulin compared to $\mathrm{C}$ group, which indicates impairment in carbohydrates metabolism. The sugar intake leads to an increase in the insulin levels, hormone responsible by the glucose absorption by tissues [31]. Hyperinsulinemia stimulates and increase the leptin secretion by the adipose tissue through PI3K/Akt/mTOR pathway [32], leading to a decrease in the appetite and an increase in the energy expenditure [33]. In agreement with this finding, the groups presented the same caloric intake; however, the HSF group showed lower chow intake, dietary efficiency, and body weight with no increased adiposity index, confirming the leptin effects.

Hypertriglyceridemia and hyperuricemia were also observed in the HSF group as consequence of the diet. High triglycerides levels can be leaded directly by two diet components: 1) the lard, which is composed mostly of saturated and monounsaturated fatty acids [34], whose ingestion is associated with elevated plasma levels of triglycerides [35];2) the fructose, a simple carbohydrate found in sucrose [36] of drinking water and also in the chow. Fructose is absorbed in the intestine through the portal vein and metabolized in the liver, following different metabolic pathways to generate energy substrates such as glucose, glycogen, lactate and fatty acids. In opposition to glucose, fructose breakdown is not regulated by the main glycolysis limiting step at the phosphofructokinase level, acting as a substrate for new hepatic lipogenesis and lipid production, which can also explain the hypertriglyceridemia [37] [38]. Moreover, uric acid can be originated from one of the fructose degradation pathways and the excessive intake of this sugar leads to hyperuricemia [37], considered a biomarker of some cardiovascular and renal diseases [39] [40].

In addition to the metabolic and hormonal changes, the diet was also able to increase the proinflammatory cytokines levels in the adipose tissue. Adipose tissue inflammation has been suggested to exert a central role in the physiopathology of many obesity-related disorders, as insulin resistance and type II Diabetes 
Mellitus [41]. Adipocyte hypertrophy in obesity is an important source for the development of adipose tissue inflammation [42]. Since the HSF group did not present difference in adiposity index compared to $\mathrm{C}$ group, the inflammation in adipose tissue can be explained by the high leptin levels, once this hormone can upregulate the secretion of inflammatory cytokines, such as TNF- $\alpha$ and IL-6 [43] [44]. Moreover, these cytokines induce leptin expression in adipose tissue favoring a proinflammatory scenario [43], in a feedback loop.

Adiponectin level was increased in the HSF group, an unexpected result. The literature reports a negative correlation between adiponectin levels and the increase in adipose mass [45] [46] [47]. A possible explanation for this result in the present study was described by Westerink et al., (2014), showing that this adiponectin elevation is an early anti-inflammatory response due to diet quality [48]. Another explanation for the high adiponectin levels is the impairment in kidney disease, once this hormone is excreted via kidney filtration [49] and the HSF animals showed impairment in the renal function.

The renal impairment was characterized in HSF group by the increased protein/creatinine ratio and albuminuria. Total proteinuria (represented by the protein/creatinine ratio) and albuminuria are important markers of kidney damage used as prognostic indicators in patients with chronic kidney disease [50]. Moreover, albuminuria is likely a reflection of early damage to the glomerular vascular endothelium as well as decreased ability of the tubule to reabsorb urinary albumin [51]. Urinary measurement of total proteinuria includes higher molecular weight non-albumin urinary proteins as well, which may be tubular as well as glomerular in origin [52]. The changes in the renal function may be associated with the proinflammatory cytokines in adipose tissue, once these cytokines are able to reach the circulation and other organs (as kidneys), leading to a local inflammation, contributing to renal damage, fibrosis and renal chronic disease development [53] [54]. Another factor involved in the renal impairment is the increase of leptin, which induces the synthesis of type 1 collagen in mesangial cells, as well as type 4 collagen in glomerular endothelial cells contributing to extracellular matrix deposition, glomerulosclerosis, and proteinuria [55] [56] [57]. High insulin levels, also found in this experiment, interfere with mechanisms of renal injury, such as increased sympathetic activity and renal sodium reabsorption and potentiation of vascular response to angiotensin II and aldosterone [58].

\section{Conclusions}

In summary, the HSF diet leaded to an increase of glucose, triglycerides, insulin, leptin and uric acid. Moreover, the diet promoted inflammation in adipose tissue and the impairment of renal function. This was a cause-and-effect study, and it did not evaluate the mechanisms by which the alterations independent of obesity occurred; however this work could support future studies that clarify these mechanisms and that allow future interventions. 
Based on these results, it is possible to conclude that the HSF diet intake is directly involved in the development of metabolic-inflammatory disorders independent of obesity, dissociating the view that increased adiposity is the major risk factor for complications commonly found in obese individuals.

\section{Acknowledgements}

Unidade de Pesquisa Experimental da Faculdade de Medicina de BotucatuUNESP (UNIPEX), unit where the research was developed and the grants 2015/10626-0 and 2018/15294-3, São Paulo Research Foundation (FAPESP). The authors declare no conflict of interesting.

\section{Conflicts of Interest}

The authors declare no conflicts of interest regarding the publication of this paper.

\section{References}

[1] Renner, S., Blutke, A., Dobenecker, B., Dhom, G., Müller, T.D., Finan, B., et al. (2018) Metabolic Syndrome and Extensive Adipose Tissue Inflammation in Morbidly Obese Göttingen Minipigs. Molecular Metabolism, 16, 180-190. https://doi.org/10.1016/j.molmet.2018.06.015

[2] Lafontan, M. (2014) Adipose Tissue and Adipocyte Dysregulation. Diabetes \& Metabolism, 40,16-28. https://doi.org/10.1016/j.diabet.2013.08.002

[3] Klöting, N. and Blüher, M. (2014) Adipocyte Dysfunction, Inflammation and Metabolic Syndrome. Reviews in Endocrine and Metabolic Disorders, 15, 277-287. https://doi.org/10.1007/s11154-014-9301-0

[4] Skurk, T., Alberti-Huber, C., Herder, C. and Hauner, H. (2007) Relationship between Adipocyte Size and Adipokine Expression and Secretion. Journal of Clinical Endocrinology \& Metabolism, 92, 1023-1033. https://doi.org/10.1210/jc.2006-1055

[5] Minihane, A.M., Vinoy, S., Russell, W.R., Baka, A., Roche, H.M., Tuohy, K.M., et al. (2015) Low-Grade Inflammation, Diet Composition and Health: Current Research Evidence and Its Translation. British Journal of Nutrition, 114, 999-1012. https://doi.org/10.1017/S0007114515002093

[6] Calder, P.C., Ahluwalia, N., Brouns, F., Buetler, T., Clement, K., Cunningham, K., et al. (2011) Dietary Factors and Low-Grade Inflammation in Relation to Overweight and Obesity. British Journal of Nutrition, 106, S5-S78.

https://doi.org/10.1017/S0007114511005460

[7] Hart, S., Marnane, C., McMaster, C. and Thomas, A. (2018) Development of the "Recovery from Eating Disorders for Life" Food Guide (REAL Food Guide): A Food Pyramid for Adults with an Eating Disorder. Journal of Eating Disorders, 6, 6. https://doi.org/10.1186/s40337-018-0192-4

[8] Davis, C., Bryan, J., Hodgson, J. and Murphy, K. (2015) Definition of the Mediterranean Diet: A Literature Review. Nutrients, 7, 9139-9153.

https://doi.org/10.3390/nu7115459

[9] Kitabchi, A.E., McDaniel, K.A., Wan, J.Y., Tylavsky, F.A., Jacovino, C.A., Sands, C.W., et al. (2013) Effects of High-Protein versus High-Carbohydrate Diets on Markers of $\beta$-Cell Function, Oxidative Stress, Lipid Peroxidation, Proinflammatory Cytokines, and Adipokines in Obese, Premenopausal Women without Diabetes. 
Diabetes Care, 36, 1919-1925. https://doi.org/10.2337/dc12-1912

[10] Ferrucci, L., Cherubini, A., Bandinelli, S., Bartali, B., Corsi, A., Lauretani, F., et al. (2006) Relationship of Plasma Polyunsaturated Fatty Acids to Circulating Inflammatory Markers. Journal of Clinical Endocrinology \& Metabolism, 91, 439-446. https://doi.org/10.1210/jc.2005-1303

[11] Ma, Y., Griffith, J.A., Chasan-Taber, L., Olendzki, B.C., Jackson, E., Stanek, E.J., et al. (2006) Association between Dietary Fiber and Serum C-Reactive Protein. American Journal of Clinical Nutrition, 83, 760-766. https://doi.org/10.1093/ajcn/83.4.760

[12] Bertran, N., Camps, J., Fernandez-Ballart, J., Arija, V., Ferre, N., Tous, M., et al. (2005) Diet and Lifestyle Are Associated with Serum C-Reactive Protein Concentrations in a Population-Based Study. Journal of Laboratory and Clinical Medicine, 145, 41-66. https://doi.org/10.1016/j.lab.2004.11.002

[13] Wannamethee, S.G., Lowe, G.D.O., Rumley, A., Bruckdorfer, K.R. and Whincup, P.H. (2006) Associations of Vitamin C Status, Fruit and Vegetable Intakes, and Markers of Inflammation and Hemostasis. American of Journal Clinical Nutrition, 83, 567-574. https://doi.org/10.1093/ajcn.83.3.567

[14] Hariharan, D., Vellanki, K. and Kramer, H. (2015) The Western Diet and Chronic Kidney Disease. Current Hypertension Reports, 17, 16.

[15] Tapsell, L.C., Neale, E.P., Satija, A. and Hu, F.B. (2016) Foods, Nutrients, and Dietary Patterns: Interconnections and Implications for Dietary Guidelines. Advances in Nutrition, 7, 445-454. https://doi.org/10.3945/an.115.011718

[16] Ha, E.E. and Bauer, R.C. (2018) Emerging Roles for Adipose Tissue in Cardiovascular Disease. Arteriosclerosis, Thrombosis, and Vascular Biology, 38, 137-144. https://doi.org/10.1161/ATVBAHA.118.311421

[17] Antoniades, C. (2017) "Dysfunctional” Adipose Tissue in Cardiovascular Disease: A Reprogrammable Target or an Innocent Bystander? Cardiovascular Research, 113, 997-998. https://doi.org/10.1093/cvr/cvx116

[18] Abranches, M.V., De Oliveira, F.C.E., Da Conceição, L.L. and Peluzio, M.D.C.G. (2015) Obesity and Diabetes: The Link between Adipose Tissue Dysfunction and Glucose Homeostasis. Nutrition Research Reviews, 28, 121-132. https://doi.org/10.1017/S0954422415000098

[19] Hajer, G.R., van Haeften, T.W. and Visseren, F.L.J. (2008) Adipose Tissue Dysfunction in Obesity, Diabetes, and Vascular Diseases. European Heart Journal, 29, 2959-2971. https://doi.org/10.1093/eurheartj/ehn387

[20] Gold, M.R., Thébault, C., Linde, C., Abraham, W.T., Gerritse, B., Ghio, S., et al. (2012) Effect of QRS Duration and Morphology on Cardiac Resynchronization Therapy Outcomes in Mild Heart Failure: Results from the Resynchronization Reverses Remodeling in Systolic Left Ventricular Dysfunction (REVERSE) Study. Circulation, 126, 822-829. https://doi.org/10.1161/CIRCULATIONAHA.112.097709

[21] Lambert, C., Cubedo, J., Padró, T., Vilahur, G., López-Bernal, S., Rocha, M., et al. (2018) Effects of a Carob-Pod-Derived Sweetener on Glucose Metabolism. Nutrients, 10, pii: E271. https://doi.org/10.3390/nu10030271

[22] Canadian Council on Animal Care (1993) Guide to the Care and Use of Experimental Animals.

https://www.aaalac.org/accreditation/RefResources/CCAC_Experimental_Animals_ Vol1.pdf

[23] Francisqueti, F., Minatel, I., Ferron, A., Bazan, S., Silva, V., Garcia, J., et al. (2017) 
Effect of Gamma-Oryzanol as Therapeutic Agent to Prevent Cardiorenal Metabolic Syndrome in Animals Submitted to High Sugar-Fat Diet. Nutrients, 9, 1299. https://doi.org/10.3390/nu9121299

[24] Nascimento, A.F., Sugizaki, M.M., Leopoldo, A.S., Lima-Leopoldo, A.P., Nogueira, C.R., Novelli, E.L.B., et al. (2008) Misclassification Probability as Obese or Lean in Hypercaloric and Normocaloric Diet. Biological Research, 41, 253-259.

https://doi.org/10.4067/S0716-97602008000300002

[25] Oliveira Junior, S.A., Dal Pai-Silva, M., Martinez, P.F., Campos, D.H.S., Lima-Leopoldo, A.P., Leopoldo, A.S., et al. (2010) Differential Nutritional, Endocrine, and Cardiovascular Effects in Obesity-Prone and Obesity-Resistant Rats Fed Standard and Hypercaloric Diets. Medicine Science Monitor, 16, BR208-BR217.

[26] Dobrian, A.D., Davies, M.J., Schriver, S.D., Lauterio, T.J. and Prewitt, R.L. (2001) Oxidative Stress in a Rat Model of Obesity-Induced Hypertension. Hypertension, 37, 554-560. https://doi.org/10.1161/01.HYP.37.2.554

[27] Chen, J.Y., Jian, D.Y., Lien, C.C., Lin, Y.T., Ting, C.H., Chen, L.K., et al. (2016) Adipocytes Play an Etiological Role in the Podocytopathy of High-Fat Diet-Fed Rats. Journal of Endocrinology, 231, 109-120. https://doi.org/10.1530/JOE-16-0064

[28] Matthews, D.R., Hosker, J.P., Rudenski, A.S., Naylor, B.A., Treacher, D.F. and Turner, R.C. (1985) Homeostasis Model Assessment: Insulin Resistance and Beta-Cell Function from Fasting Plasma Glucose and Insulin Concentrations in Man. Diabetologia, 28, 412-419. https://doi.org/10.1007/BF00280883

[29] Luvizotto, R.A.M., Nascimento, A.F., Imaizumi, E., Pierine, D.T., Conde, S.J., Correa, C.R., et al. (2013) Lycopene Supplementation Modulates Plasma Concentrations and Epididymal Adipose Tissue mRNA of Leptin, Resistin and IL-6 in Diet-Induced Obese Rats. British Journal of Nutrition, 110, 1803-1809. https://doi.org/10.1017/S0007114513001256

[30] Fruh, S.M. (2017) Obesity: Risk Factors, Complications, and Strategies for Sustainable Long-Term Weight Management. Journal of the American Association of Nurse Practitioners, 29, 3-14. https://doi.org/10.1002/2327-6924.12510

[31] Marcelino, H., Veyrat-durebex, C., Summermatter, S., Sara, D., Miles-chan, J., Arsenijevic, D., et al. (2013) A Role for Adipose Tissue De Novo Lipogenesis in Glucose Homeostasis during Catch-Up Growth a Randle Cycle Favoring Fat Storage. Diabetes, 62, 362-372. https://doi.org/10.2337/db12-0255

[32] Lima, W.G. and Silva, H.M. (2018) Insulin as a Hormone Regulator of the Synthesis and Release of Leptin by White Adipose Tissue. Peptides, 106, 9-58.

https://doi.org/10.1016/j.peptides.2018.06.007

[33] Zhang, Y. and Chua, S. (2017) Leptin Function and Regulation. Comprehensive Physiology, 8, 351-369. https://doi.org/10.1002/cphy.c160041

[34] Crescenzo, R., Bianco, F., Mazzoli, A., Giacco, A., Cancelliere, R., di Fabio, G., et al. (2015) Fat Quality Influences the Obesogenic Effect of High Fat Diets. Nutrients, 7, 9475-9491. https://doi.org/10.3390/nu7115480

[35] Gonzalez, M.M., Timerman, S., Gianotto-Oliveira, R., Polastri, T.F., Canesin, M.F., Schimidt, A., et al. (2013) I Diretriz de Ressuscitação Cardiovasculares de Emergência da Sociedade Brasileira de Cardiologia. Arquivos Brasileiros de Cardiologia, 101, 3-221. https://doi.org/10.5935/abc.2013S006

[36] Tran, L.T., Yuen, V.G. and McNeill, J.H. (2009) The Fructose-Fed Rat: A Review on the Mechanisms of Fructose-Induced Insulin Resistance and Hypertension. Molecular and Cellular Biochemistry, 332, 145-159. https://doi.org/10.1007/s11010-009-0184-4 
[37] Legeza, B., Marcolongo, P., Gamberucci, A., Varga, V., Benedetti, A. and Odermatt, A. (2017) Fructose, Glucocorticoids and Adipose Tissue: Implications for the Metabolic Syndrome, Nutrients, 9, pii: E426. https://doi.org/10.3390/nu9050426

[38] Zhang, D.M., Jiao, R.Q. and Kong, L.D. (2017) High Dietary Fructose: Direct or Indirect Dangerous Factors Disturbing Tissue and Organ Functions. Nutrients, 9, pii: E335. https://doi.org/10.3390/nu9040335

[39] Stack, A.G., Hanley, A., Casserly, L.F., Cronin, C.J., Abdalla, A.A., Kiernan, T.J., et al. (2013) Independent and Conjoint Associations of Gout and Hyperuricaemia with Total and Cardiovascular Mortality. QJM: An International Journal of Medicine, 106, 647-658. https://doi.org/10.1093/qjmed/hct083

[40] Caliceti, C., Calabria, D., Roda, A. and Cicero, A. (2017) Fructose Intake, Serum Uric Acid, and Cardiometabolic Disorders: A Critical Review. Nutrients, 9, pii: E395. https://doi.org/10.3390/nu9040395

[41] Burhans, M.S., Hagman, D.K., Kuzma, J.N., Schmidt, K.A. and Kratz, M. (2019) Contribution of Adipose Tissue Inflammation to the Development of Type $2 \mathrm{Di}$ abetes Mellitus. Comprehensive Physiology, 9, 1-58.

https://doi.org/10.1002/cphy.c170040

[42] Jenndahl, L.E., Hammarstedt, A. and Henninger, A.M.J. (2014) Adipocyte Hypertrophy, Inflammation and Fibrosis Characterize Subcutaneous Adipose Tissue of Health, Non-Obese Subjects Predisposed to Type 2 Diabetes. PLoS ONE, 9, e105262. https://doi.org/10.1371/journal.pone.0105262

[43] Iikuni, N., Lam, Q.L.K., Lu, L., Matarese, G. and La Cava, A. (2010) Leptin and Inflammation. Current Immunology Reviews, 4, 70-79. https://doi.org/10.2174/157339508784325046

[44] La Cava, A. (2017) Leptin in Inflammation and Autoimmunity. Cytokine, 98, 51-58. https://doi.org/10.1016/j.cyto.2016.10.011

[45] Sarraf, P., Frederich, R.C., Turner, E.M., Ma, G., Jaskowiak, N.T., Rivet, D.J., et al. (1997) Multiple Cytokines and Acute Inflammation Raise Mouse Leptin Levels: Potential Role in Inflammatory Anorexia. Journal of Experimental Medicine, 185, 171-175. https://doi.org/10.1084/jem.185.1.171

[46] Kershaw, E.E. and Flier, J.S. (2004) Adipose Tissue as an Endocrine Organ. Journal of Clinical Endocrinology and Metabolism, 89, 2548-2556. https://doi.org/10.1210/jc.2004-0395

[47] Opatrilova, R., Caprnda, M., Kubatka, P., Valentova, V., Uramova, S., Nosal, V., et al. (2018) Adipokines in Neurovascular Diseases. Biomedicine and Pharmacotherapy, 98, 424-432. https://doi.org/10.1016/j.biopha.2017.12.074

[48] Westerink, J., Hajer, G.R., Kranendonk, M.E.G., Schipper, H.S., Monajemi, H., Kalkhoven, E., et al. (2014) An Oral Mixed Fat Load Is Followed by a Modest Anti-Inflammatory Adipocytokine Response in Overweight Patients with Metabolic Syndrome. Lipids, 49, 247-254. https://doi.org/10.1007/s11745-014-3877-8

[49] Navarro, M.E., Santos, K.C., Nascimento, A.F., Francisqueti, F.V., Minatel, I.O., Pierine, D.T., Luvizotto, R.A., Ferreira, A.L.A. and Campos, D.H.S. (2016) Renal Inflammatory and Oxidative and Metabolic Changes after 6 Weeks of Cafeteria Diet in Rats. Brazilian Journal of Nephrology, 38, 9-14. https://doi.org/10.5935/0101-2800.20160003

[50] Annigeri, R., Vadamalai, V., Seshadri, R., Balasubramanian, S., Rao, B., Kowdle, P., et al. (2013) Accuracy of Spot Urine Protein Creatinine Ratio in Measuring Proteinuria in Chronic Kidney Disease Stage 3 and 4. Indian Journal of Nephrology, 23, 428-433. https://doi.org/10.4103/0971-4065.120340 
[51] Satchell, S.C. and Tooke, J.E. (2008) What Is the Mechanism of Microalbuminuria in Diabetes: A Role for the Glomerular Endothelium? Diabetologia, 51, 714-725. https://doi.org/10.1007/s00125-008-0961-8

[52] Fisher, H., Hsu, C., Vittinghoff, E., Lin, F. and Bansal, N. (2013) Comparison of Assiociations of Urine Protein-Creatinine Ratio versus Albumin-Creatinine Ratio with Complications of CKD: A Cross-Sectional Analysis. American Journal of Kidney Diseases, 62, 1102-1108. https://doi.org/10.1053/j.ajkd.2013.07.013

[53] Mills, K.T., Hamm, L.L., Alper, A.B., Miller, C., Hudaihed, A., Balamuthusamy, S., et al. (2013) Circulating Adipocytokines and Chronic Kidney Disease. PLOS ONE, 8, e76902. https://doi.org/10.1371/journal.pone.0076902

[54] Rüster, C. and Wolf, G. (2013) Adipokines Promote Chronic Kidney Disease. Nephrology Dialysis Transplantation, 28, 8-14. https://doi.org/10.1093/ndt/gft191

[55] Tesauro, M., Canale, M.P., Rodia, G., Di Daniele, N., Lauro, D., Scuteri, A., et al. (2011) Metabolic Syndrome, Chronic Kidney, and Cardiovascular Diseases: Role of Adipokines. Cardiology Research Practice, 2011, Article ID: 653182. https://doi.org/10.4061/2011/653182

[56] Ballermann, B.J. (1999) A Role for Leptin in Glomerulosclerosis? Kidney International, 56, 1154-1155. https://doi.org/10.1046/j.1523-1755.1999.00650.x

[57] Wolf, G. and Ziyadeh, F.N. (2006) Leptin and Renal Fibrosis. Contributions to Nephrology, 151, 175-183. https://doi.org/10.1159/000095328

[58] Biddinger, S.B. and Kahn, C.R. (2006) From Mice to Men: Insights into the Insulin Resistance Syndromes. Annual Review of Physiology, 68, 123-158.

https://doi.org/10.1146/annurev.physiol.68.040104.124723 